\title{
Clinical development of S-1 plus cisplatin therapy as first-line treatment for advanced gastric cancer
}

\author{
WASABuro KoIZumi \\ Department of Internal Medicine, Kitasato University School of Medicine, 2-1-1 Asamizodai, Sagamihara, Kanagawa 228-8520, Japan
}

\begin{abstract}
We reviewed the clinical development of S-1 and S-1 plus cisplatin (CDDP) therapy for advanced gastric cancer (AGC). S-1 is an active oral fluoropyrimidine in patients with AGC. Phase I/II clinical trials of S-1 plus CDDP for AGC have yielded high response rates and the agents were well tolerated. On the basis of these phase I/II studies, we performed a randomized phase III study comparing S-1 plus CDDP with S-1 alone in patients with AGC. In the S-1 plus CDDP group, S-1 was given orally, twice daily for 3 consecutive weeks, and $60 \mathrm{mg} / \mathrm{m}^{2}$ CDDP was given intravenously on day 8 , followed by a 2-week rest period, within a 5-week cycle. In the S-1 alone group, S-1 was given orally, twice daily for 4 consecutive weeks, followed by 2 weeks of rest, within a 6-week cycle. Median overall survival was significantly longer in the S-1 plus CDDP group (13.0 months) than in the $S-1$ alone group (11.0 months; $P=0.04)$. Progression-free survival was significantly longer in the S-1 plus CDDP group (median, 6.0 months vs 4.0 months; $P<0.0001)$ and the response rate was also significantly higher $(54.0 \%$ vs $31.1 \% ; P=0.002)$. There were more grade 3 or 4 adverse events, including leukopenia, neutropenia, anemia, nausea, and anorexia in the S-1 plus CDDP group, but the events were manageable. No treatment-related deaths were observed. As a result of this study, S-1 plus CDDP therapy has become a standard first-line treatment for AGC in Japan.
\end{abstract}

Key words S- 1 CDDP · Gastric cancer

\section{Introduction}

Gastric cancer is particularly prevalent in East Asia, Eastern Europe, and Central and South America. Worldwide, gastric cancer remains the second cause of death from cancer, with about 700000 confirmed deaths

Offprint requests to: W. Koizumi

Received: September 8, 2008 / Accepted: October 8, 2008 annually $[1,2]$. In Japan, gastric cancer is one of the most frequent causes of death from cancer, despite dramatic advances in diagnosis and therapy [3]. Outcomes are extremely poor among patients with unresectable gastric cancer, with the median survival ranging from 3 to 5 months with the best supportive care [4-6].

Randomized controlled trials of various treatment regimens have produced disappointing results in patients with advanced gastric cancer (AGC), with survival of only 6 to 11 months. Median survival times (MSTs) have gradually improved, but are still less than 1 year [7-13]. Standard treatments remain a matter of debate.

In this context, we evaluated the effectiveness of S-1 plus cisplatin (CDDP) therapy in a randomized phase III study based on the promising activity of several clinical studies of S-1. This review focuses on the clinical development of S-1 and S-1 plus CDDP therapy for AGC.

\section{Drug concept of S-1}

S-1 (TS-1; Taiho Pharmaceutical, Tokyo, Japan) is an oral anticancer drug that combines tegafur (FT), a prodrug of 5-fluorouracil (5-FU), with 5-chloro-2, 4dihydropyridine (CDHP; gimeracil) and potassium oxonate (Oxo; oteracil potassium) in a molar ratio of 1:0.4:1. CDHP reversibly antagonizes the activity of dihydropyrimidine dehydrogenase (DPD), the ratelimiting enzyme for the degradation of 5-FU. CDHP has 180-fold higher DPD inhibitory activity than that of uracil in vitro [14]. High concentrations of 5-FU in serum and tumors are thereby maintained for prolonged periods. Potassium oxonate blocks the phosphorylation of 5-FU in the gastrointestinal tract, reducing gastrointestinal adverse effects, the prime dose-limiting toxicity of 5-FU [15]. 


\section{Pharmacokinetics of S-1 in cancer patients}

Hirata et al. [16] investigated the pharmacokinetics of 5-FU, intact FT, CDHP, and Oxo, after single or consecutive administration of $\mathrm{S}-1$, at a standard dose of $80 \mathrm{mg} / \mathrm{m}^{2}$ per day, in patients with advanced cancer ( $n$ =12). The initial dose of S- 1 for each patient was determined according to body surface area (BSA) as follows: for BSA less than $1.25 \mathrm{~m}^{2}, 80 \mathrm{mg}$ /day; for BSA $1.25 \mathrm{~m}^{2}$ to $1.5 \mathrm{~m}^{2}, 100 \mathrm{mg} / \mathrm{day}$; and for BSA more than $1.5 \mathrm{~m}^{2}$, $120 \mathrm{mg} /$ day. For single administration, half of the standard dose was administered. For 28-day consecutive administration, the standard dose was given daily in two divided doses after breakfast and dinner. The actual average single dose per BSA was $35.9 \mathrm{mg} / \mathrm{m}^{2}$ (range, $31.7-39.7 \mathrm{mg} / \mathrm{m}^{2}$ ). Pharmacokinetic parameters of plasma 5-FU were as follows: Cmax, $128.5 \pm 41.5 \mathrm{ng} / \mathrm{ml}$; Tmax, $3.5 \pm 1.7 \mathrm{~h} ; \mathrm{AUC}_{0-14}, 723.9 \pm 272.7 \mathrm{ng} \cdot \mathrm{h} / \mathrm{ml}$; and $\mathrm{T}_{1 / 2}, 1.9 \pm 0.4 \mathrm{~h}$. In the 28-day consecutive regimen, there was no drug accumulation. These data indicated that the pharmacokinetics of orally administered S- 1 were comparable to those of continuous infusion of 5-FU.

Subsequently, Yamada et al. [17] compared the pharmacokinetics of oral S-1 at the standard dose (the median actual dose of $\mathrm{S}-1$ was $71.6 \mathrm{mg} / \mathrm{m}^{2}$ per day) with those of protracted venous infusion (PVI) of $250 \mathrm{mg} / \mathrm{m}^{2}$ 5 -FU within the same AGC patients $(n=10)$. They found that oral S-1, at the present recommended doses in Japan, produced a higher Cmax $(230 \pm 69 \mathrm{ng} / \mathrm{ml}$ for S-1 vs $93 \pm 13 \mathrm{ng} / \mathrm{ml}$ for PVI of 5-FU) and a greater AUC $(1364 \pm 374 \mathrm{ng} \cdot \mathrm{h} / \mathrm{ml}$ for S-1 vs $728 \pm 113 \mathrm{ng} \cdot \mathrm{h} / \mathrm{ml}$ for PVI of 5-FU) of plasma 5-FU than did PVI of 5-FU, with no elevation of the plasma concentration of $\alpha$ fluoro- $\beta$-alanine, a catabolite of 5 -FU that is thought to cause the cardiotoxic and neurotoxic effects of 5-FU by inhibiting the tricarboxylic acid cycle [18-20].

\section{S-1 monotherapy for advanced gastric cancer (AGC)}

An early phase II study of S-1 has reported a high response rate of $53.6 \%$ in patients with AGC [21]. In two subsequent late phase II registration studies, S-1 demonstrated excellent activity for gastric cancer, with response rates of $49 \%(25 / 51)$ and $40 \%$ (20/50), respectively $[22,23]$. The median survival times obtained in these studies were 250 days and 207 days, although the treatment regimen was single-agent S-1. As for the safety of the regimen, an incidence of $10 \%-20 \%$ of grade 3 or more adverse reactions, including leukopenia, neutropenia, decreased hemoglobin, and diarrhea was observed. However, the toxicity profile of S-1 was generally mild and there were no severe or unexpected adverse reactions. Based on these results, S-1 was approved for the treatment of gastric cancer by the
Ministry of Health, Labour, and Welfare (MHLW) of Japan, in 1999.

Furthermore, the results of Japanese nationwide post-marketing studies in patients with AGC confirmed that the safety and efficacy profiles of S-1 were similar to those seen in the registration study $(n=3801)$ [24]. For these reasons, S-1 has already been used as a firstline treatment for AGC patients in Japan.

A Japan Clinical Oncology Group (JCOG) study,(the JCOG9205 study) obtained similar MSTs, of about 7 months, with both 5-FU alone and 5-FU plus CDDP in patients with unresectable AGC in a randomized phase III study [10]. Subsequent clinical trials in Japan therefore included 5-FU monotherapy as the reference arm. The JCOG9912 study by Boku et al. [25] was designed to test the hypotheses that S-1 alone was not inferior to 5-FU alone, used as a control, and that irinotecan plus CDDP was superior to 5-FU alone in patients with advanced, unresectable, or recurrent gastric cancer. In their study, although irinotecan plus CDDP was not superior to 5-FU alone, S-1 was not inferior to the 5FU-alone regimen in terms of survival as the primary endpoint. In the S-1 group and the 5-FU alone group, median survival times were 11.4 months and 10.8 months, progression-free survivals were 4.2 months and 2.9 months, and $28 \%$ and $9 \%$ of patients responded, respectively. Thus, S-1 monotherapy actually became a new standard treatment option for AGC patients in Japan.

\section{Clinical development of S-1 plus CDDP (SP) therapy}

Cisplatin (CDDP) is also a key drug for the chemotherapy of AGC. Combinations of 5-FU and CDDP were shown to be synergistic in preclinical [26-28] and clinical studies [29] of AGC, with acceptable toxicity. Based on these studies and the promising activity of S-1 observed in the late phase II studies, we conducted a phase I/II study of S-1 in combination with CDDP. S-1 was given orally at $40 \mathrm{mg} / \mathrm{m}^{2}$ b.i.d. for 21 consecutive days followed by a 2-week rest. CDDP was planned to be given intravenously on day 8 , at a dose of 60,70 , or $80 \mathrm{mg} / \mathrm{m}^{2}$ depending on the dose-limiting toxicity (DLT). In the phase I portion, the maximum tolerated dose of CDDP was presumed to be $70 \mathrm{mg} / \mathrm{m}^{2}$, because $33.3 \%$ of patients $(2 / 6)$ developed DLTs, mainly neutropenia. Therefore, the recommended dose (RD) of CDDP combined with $80 \mathrm{mg} / \mathrm{m}^{2}$ of S-1 was estimated to be $60 \mathrm{mg} / \mathrm{m}^{2}$. Plasma pharmacokinetic analysis was performed on samples obtained from 12 patients during the first course of the phase I portion. CDDP did not affect the plasma pharmacokinetics of any S-1 component, which was considered to be safely administered in this combination regimen. 
In the phase II portion, the efficacy and safety of the regimen was evaluated in 19 patients, including 6 patients in the RD level in the phase I portion. The median number of cycles administered was four (range, $1-8)$. The incidences of grade 3 or more hematological and nonhematological toxicities were $15.8 \%$ and $26.3 \%$, respectively, but all were manageable. The objective response rate was $74 \%(14 / 19 ; 95 \%$ confidence interval [CI], 54.9\%-90.6\%), and the median survival time was 383 days.

Thus, this regimen was considered to be promising against AGC, with acceptable toxicity.

\section{Randomized phase III study of S-1 plus CDDP therapy for advanced gastric cancer (AGC)}

Based on a previous phase I/II study, we conducted a randomized phase III study of S-1 plus CDDP therapy which was compared to S-1 monotherapy (designated as the SPIRITS trial: S-1 Plus CDDP versus S-1 In RCT In the Treatment for Stomach Cancer) [30]. The primary objective of this phase III study was to determine whether the S-1 plus CDDP therapy (group SP) was superior to $\mathrm{S}-1$ monotherapy (group $\mathrm{S}$ ) in terms of overall survival. In the S-1 plus CDDP group, S-1 was given orally, twice daily for 3 consecutive weeks, and $60 \mathrm{mg} / \mathrm{m}^{2}$ CDDP was given intravenously on day 8 , followed by a 2 -week rest period, within a 5-week cycle. In the S-1 alone group, S-1 was given orally, twice daily for 4 consecutive weeks, followed by 2 weeks of rest, within a 6-week cycle. A total of 305 patients were registered at 38 centers in Japan from March 2002 through November 2004 and randomly assigned to the two treatment groups. At study enrollment, there was no significant difference between the treatment groups regarding any single clinical characteristic. No patient had locally advanced disease alone. Histologically, diffuse-type and intestinal-type adenocarcinomas, respectively, were diagnosed in 103 patients $(70 \%)$ and 45 patients (30\%) in group SP, as compared with $89(59 \%)$ and $60(40 \%)$ in group S, indicating a worse outcome to be expected in group SP than in group S [31].

Median follow-up was 2 years and 11 months. Median overall survival as the primary endpoint was significantly longer in group SP than in group S (13.0 months vs 11.0 months; $P=0.04$ ). The hazard ratio (HR) for death was 0.77 (95\% CI, 0.61 to 0.98$)$. Median progression-free survival as a secondary endpoint was significantly longer in group SP than in group $\mathrm{S}(6.0$ months vs 4.0 months; $P<0.0001)$. The HR for disease progression was 0.57 (95\% CI, 0.44 to 0.73 ).

Among the 87 patients with target lesions in group SP, 1 had a complete response and 46 had partial responses, for a response rate of $54.0 \%$ (95\% CI, $43.0 \%$ to $64.8 \%$ ). Of the 106 patients with target lesions in group S, 1 had a complete response and 32 had partial responses, yielding a response rate of $31.1 \%(95 \% \mathrm{CI}$, 22.5 to 40.9$)$. The response rate was significantly higher in group SP $(P=0.002)$.

The incidences of grade 3 or 4 hematological adverse events in group SP and group S were mainly as follows: leukopenia, $11.5 \%$ vs $2.0 \%$; neutropenia, $39.9 \%$ vs $10.7 \%$; and anemia, $25.7 \%$ vs $4.0 \%$. The incidence of febrile neutropenia was $3.4 \%$ in group SP and $1.3 \%$ in group S. The incidences of grade 3 or 4 nonhematological adverse events in group SP and group S were mainly as follows: anorexia, $30.4 \%$ vs $6.0 \%$; nausea, $11.5 \%$ vs $1.3 \%$; vomiting, $4.1 \%$ vs $2.0 \%$; fatigue, $4.1 \%$ v. $1.3 \%$; and diarrhea, $4.1 \%$ vs $3.3 \%$. There were no treatmentrelated deaths in either group.

The median initial actual dose of S-1 was $36.1 \mathrm{mg} / \mathrm{m}^{2}$ b.i.d. (range, $31.7-39.8 \mathrm{mg} / \mathrm{m}^{2}$ ) in group $\mathrm{SP}$ and $36.0 \mathrm{mg} /$ $\mathrm{m}^{2}$ b.i.d. (range, $28.8-39.9 \mathrm{mg} / \mathrm{m}^{2}$ ) in group $\mathrm{S}$; i.e., the dose was similar in the two groups. The median relative dose intensity was $93.3 \%$ for the scheduled cycles of therapy in group SP, as compared with $98.0 \%$ in group $\mathrm{S}$. Median time to treatment failure was 4.8 months in group SP and 3.9 months in group $\mathrm{S}(P=0.009$; HR, 0.699; 95\% CI, 0.536-0.912).

In summary, we concluded that the S-1 plus CDDP therapy was superior to $\mathrm{S}-1$ monotherapy, with a favorable toxicity profile.

In recent previous phase III clinical trials of chemotherapy in patients with gastric cancer, the following median survival times have been reported: 9.2 months for docetaxel and CDDP plus 5-FU (DCF) by the V325 Study Group [11], 10.5 months for a combination of capecitabine and CDDP (XP) by Kang et al. [8]; and 9.9 months for a combination of epirubicin, CDDP, and 5-FU (ECF) and 11.2 months for a combination of capecitabine, oxaliplatin, and epirubicin (EOX) in the REAL2 trial [7]. No previously reported well-tolerated chemotherapy regimen in patients with AGC has obtained a median survival time of 1 year or longer (Table 1). We hypothesized that the median survival time of longer than 1 year and the median progressionfree survival of 6.0 months was ascribable to synergism between S-1 and CDDP. Furthermore, this is also the first phase III trial to show better results with combination chemotherapy than monotherapy. These results suggest that S-1 plus CDDP may represent just one step in the process of developing a standard treatment for AGC, although we need to consider the fact that therapeutic outcomes in Japan are generally better than those in Western trials.

Most recently, the Chinese SC-101 study revealed that S-1 plus CDDP therapy was superior to 5-FU plus CDDP therapy, with the response rate as the primary 
Table 1. Recent randomized phase III studies in advanced gastric cancer

\begin{tabular}{|c|c|c|c|c|c|c|}
\hline Author & Regimen & $n$ & RR (\%) & PFS (months) & OS (months) & $P$ value (OS) \\
\hline \multirow[t]{2}{*}{ Koizumi et al. [30] (2008) } & S-1 & 150 & 31 & 4.0 & 11.0 & \\
\hline & $\mathrm{S}-1+\mathrm{CDDP}$ & 148 & 54 & 6.0 & 13.0 & 0.04 \\
\hline \multirow{3}{*}{ Jin et al. [32] (2008) } & S-1 & 77 & 25 & - & 8.9 & \\
\hline & $\mathrm{S}-1+\mathrm{CDDP}$ & 74 & 38 & - & 14.4 & $<0.001,{ }^{\mathrm{a}} 0.038^{\mathrm{b}}$ \\
\hline & $5-\mathrm{FU}+\mathrm{CDDP}$ & 73 & 19 & - & 10.3 & \\
\hline \multirow[t]{3}{*}{ Boku et al. [25] (2007) } & $5-\mathrm{FU}$ & 234 & 9 & 2.9 & 10.8 & \\
\hline & CPT-11/CDDP & 236 & 38 & 4.8 & 12.3 & 0.055 \\
\hline & S-1 & 234 & 28 & 4.2 & 11.4 & $<0.001^{\mathrm{c}}$ \\
\hline \multirow[t]{3}{*}{ Ohtsu et al. [10] (2003) } & $5-\mathrm{FU}$ & 105 & 11 & 1.9 & 7.1 & NS \\
\hline & $\mathrm{UFT}+\mathrm{MMC}$ & 70 & 9 & 2.4 & 6.0 & \\
\hline & $5-\mathrm{FU}+\mathrm{CDDP}$ & 105 & 34 & 3.9 & 7.3 & \\
\hline \multirow[t]{2}{*}{ Van Cutsem et al. [11] (2006) } & $\mathrm{CF}$ & 224 & 25 & $3.7^{\mathrm{d}}$ & 8.6 & \\
\hline & $\mathrm{DCF}$ & 221 & 37 & 5.6 & 9.2 & 0.02 \\
\hline \multirow[t]{4}{*}{ Cunningham et al. [7] (2008) } & $\mathrm{ECF}$ & 263 & 41 & 6.2 & 9.9 & NS \\
\hline & $\mathrm{EOF}$ & 245 & 42 & 6.5 & 9.3 & \\
\hline & ECX & 250 & 46 & 6.7 & 9.9 & \\
\hline & EOX & 244 & 48 & 7.0 & 11.2 & \\
\hline \multirow{2}{*}{ Kang et al. [8] (2006) } & FP & 137 & 29 & 5.0 & 9.3 & NS \\
\hline & $\mathrm{XP}$ & 139 & 41 & 5.6 & 10.5 & \\
\hline
\end{tabular}

RR, response rate; PFS, progression-free survival; OS, overall survival

${ }^{\mathrm{a}}$ vs $\mathrm{S}-1$

${ }^{\mathrm{b}}$ vs $5-\mathrm{FU}+\mathrm{CDDP}$

${ }^{\mathrm{c}}$ Noninferiority

${ }^{\mathrm{d}}$ Time to tumor progression

endpoint [32]. In this study, the overall survival with S-1 plus CDDP therapy was also superior to those of both the 5-FU plus CDDP therapy and the S-1 alone regimen. These data suggests that S-1 plus CDDP therapy may provide a favorable outcome, at least in Asian populations.

At present, a large randomized controlled trial, the First-Line Advanced Gastric Cancer Study (FLAGS) is being conducted in 24 countries to determine whether S-1 plus CDDP is superior to 5-FU plus CDDP. In the FLAGS trial, the enrollment of about 1000 patients has recently been completed, and the results are pending [33].

\section{Conclusion}

We believe that our results will establish S-1 plus CDDP as a standard treatment for gastric cancer in Japan, and as such, the SPIRITS study can be considered to be a clinical practice-changing trial. Further studies are warranted to investigate the $\mathrm{S}-1$ plus CDDP regimen as a cytotoxic backbone in combination with novel targeted agents.

\section{References}

1. Kamangar F, Dores GM, Anderson WF. Patterns of cancer incidence, mortality, and prevalence across five continents: defining priorities to reduce cancer disparities in different geographic regions of the world. J Clin Oncol 2006;24:2137-50.
2. Muñoz N, Franceschi S. Epidemiology of gastric cancer and perspectives for prevention. Salud Pública Méx 1997;39:318-30.

3. Inoue M, Tsugane S. Epidemiology of gastric cancer in Japan. Postgrad Med J 2005;81:419-24.

4. Glimelius B, Ekstrom K, Hoffman K, Graf W, Sjoden PO, Haglund U, et al. Randomized comparison between chemotherapy plus best supportive care with best supportive care in advanced gastric cancer. Ann Oncol 1997;8:163-8.

5. Murad AM, Santiago FF, Petroianu A, Rocha PR, Rodrigues MA, Rausch M. Modified therapy with 5-fluorouracil, doxorubicin, and methotrexate in advanced gastric cancer. Cancer 1993;72:37-41.

6. Pyrhönen S, Kuitunen T, Nyandoto P, Kouri M. Randomised comparison of fluorouracil, epidoxorubicin and methotrexate (FEMTX) plus supportive care with supportive care alone in patients with non-resectable gastric cancer. Br J Cancer 1995;71: 587-91.

7. Cunningham D, Starling N, Rao S, Iveson T, Nicolson M, Coxon F, et al. Capecitabine and oxaliplatin for advanced esophagogastric cancer. N Engl J Med 2008;358:36-46.

8. Kang Y, Kang WK, Shin DB, Chen J, Xiong J, Wang J, et al. Randomized phase III trial of capecitabine/cisplatin (XP) vs continuous infusion of 5-FU/cisplatin (FP) as first-line therapy in patients (pts) with advanced gastric cancer (AGC): Efficacy and safety results. J Clin Oncol (Meeting Abstracts) 2006;24: LBA4018.

9. Kim NK, Park YS, Heo DS, Suh C, Kim SY, Park KC, et al. A phase III randomized study of 5-fluorouracil and cisplatin versus 5-fluorouracil, doxorubicin, and mitomycin $\mathrm{C}$ versus 5fluorouracil alone in the treatment of advanced gastric cancer. Cancer 1993;71:3813-8.

10. Ohtsu A, Shimada Y, Shirao K, Boku N, Hyodo I, Saito H, et al. Randomized phase III trial of fluorouracil alone versus fluorouracil plus cisplatin versus uracil and tegafur plus mitomycin in patients with unresectable, advanced gastric cancer: The Japan Clinical Oncology Group Study (JCOG9205). J Clin Oncol 2003;21:54-9.

11. Van Cutsem E, Moiseyenko VM, Tjulandin S, Majlis A, Constenla M, Boni C, et al. Phase III study of docetaxel and cisplatin 
plus fluorouracil compared with cisplatin and fluorouracil as firstline therapy for advanced gastric cancer: a report of the V325 Study Group. J Clin Oncol 2006;24:4991-7.

12. Vanhoefer U, Rougier P, Wilke H, Ducreux MP, Lacave AJ, Van Cutsem E, et al. Final results of a randomized phase III trial of sequential high-dose methotrexate, fluorouracil, and doxorubicin versus etoposide, leucovorin, and fluorouracil versus infusional fluorouracil and cisplatin in advanced gastric cancer: a trial of the European Organization for Research and Treatment of Cancer Gastrointestinal Tract Cancer Cooperative Group. J Clin Oncol 2000;18:2648-57.

13. Webb A, Cunningham D, Scarffe JH, Harper P, Norman A, Joffe $\mathrm{JK}$, et al. Randomized trial comparing epirubicin, cisplatin, and fluorouracil versus fluorouracil, doxorubicin, and methotrexate in advanced esophagogastric cancer. J Clin Oncol 1997;15:261-7.

14. Tatsumi K, Fukushima M, Shirasaka T, Fujii S. Inhibitory effects of pyrimidine, barbituric acid and pyridine derivatives on 5fluorouracil degradation in rat liver extracts. Jpn J Cancer Res 1987;78:748-55.

15. Shirasaka T, Shimamato Y, Ohshimo H, Yamaguchi M, Kato T, Yonekura K, et al. Development of a novel form of an oral 5fluorouracil derivative (S-1) directed to the potentiation of the tumor selective cytotoxicity of 5-fluorouracil by two biochemical modulators. Anticancer Drugs 1996;7:548-57.

16. Hirata K, Horikoshi N, Aiba K, Okazaki M, Denno R, Sasaki K, et al. Pharmacokinetic study of S-1, a novel oral fluorouracil antitumor drug. Clin Cancer Res 1999;5:2000-5.

17. Yamada Y, Hamaguchi T, Goto M, Muro K, Matsumura Y, Shimada Y, et al. Plasma concentrations of 5-fluorouracil and Fbeta-alanine following oral administration of S-1, a dihydropyrimidine dehydrogenase inhibitory fluoropyrimidine, as compared with protracted venous infusion of 5-fluorouracil. Br J Cancer 2003;89:816-20.

18. Akiba T, Okeda R, Tajima T. Metabolites of 5-fluorouracil, alpha-fluoro-beta-alanine and fluoroacetic acid, directly injure myelinated fibers in tissue culture. Acta Neuropathol 1996;92: 8-13.

19. Okeda R, Shibutani M, Matsuo T, Kuroiwa T, Shimokawa R, Tajima T. Experimental neurotoxicity of 5-fluorouracil and its derivatives is due to poisoning by the monofluorinated organic metabolites, monofluoroacetic acid and alpha-fluoro-beta-alanine. Acta Neuropathol 1990;81:66-73.

20. Zhang RW, Soong SJ, Liu TP, Barnes S, Diasio SB. Pharmacokinetics and tissue distribution of 2-fluoro-beta-alanine in rats. Potential relevance to toxicity pattern of 5-fluorouracil. Drug Metab Dispos 1992;20:113-9.

21. Sugimachi K, Maehara Y, Horikoshi N, Shimada Y, Sakata Y, Mitachi Y, et al. An early phase II study of oral S-1, a newly developed 5-fluorouracil derivative for advanced and recurrent gastrointestinal cancers. The S-1 Gastrointestinal Cancer Study Group. Oncology 1999;57:202-10.
22. Koizumi W, Kurihara M, Nakano S, Hasegawa K. Phase II study of S-1, a novel oral derivative of 5-fluorouracil, in advanced gastric cancer. For the S-1 Cooperative Gastric Cancer Study Group. Oncology 2000;58:191-7.

23. Sakata Y, Ohtsu A, Horikoshi N, Sugimachi K, Mitachi Y, Taguchi T. Late phase II study of novel oral fluoropyrimidine anticancer drug S-1 (1 M tegafur- $0.4 \mathrm{M}$ gimestat-1 $\mathrm{M}$ otastat potassium) in advanced gastric cancer patients. Eur J Cancer 1998;34:1715-20.

24. Nagashima F, Ohtsu A, Yoshida S, Ito K. Japanese nationwide post-marketing survey of S-1 in patients with advanced gastric cancer. Gastric Cancer 2005;8:6-11.

25. Boku N, Yamamoto S, Shirao K, Doi T, Sawaki A, Koizumi W, et al. Randomized phase III study of 5-fluorouracil (5-FU) alone versus combination of irinotecan and cisplatin (CP) versus S-1 alone in advanced gastric cancer (JCOG9912). J Clin Oncol (Meeting Abstracts) 2007;25: LBA4513.

26. Scanlon KJ, Newman EM, Lu Y, Priest DG. Biochemical basis for cisplatin and 5-fluorouracil synergism in human ovarian carcinoma cells. Proc Natl Acad Sci USA 1986;83: 8923-5.

27. Yamada Y, Saito H, Oie S, Takechi T, Nakano K, Takeda S. Experimental study of the effect of combined treatment of UFT with CDDP on human solid tumor-xenografts in nude mice (in Japanese). Gan To Kagaku Ryoho 1990;17:1327-31.

28. Shirasaka T, Shimamoto Y, Ohshimo H, Saito H, Fukushima M. Metabolic basis of the synergistic antitumor activities of 5fluorouracil and cisplatin in rodent tumor models in vivo. Cancer Chemother Pharmacol 1993;32:167-72.

29. Rougier P, Ducreux M, Mahjoubi M, Pignon JP, Bellefqih S, Oliveira J, et al. Efficacy of combined 5-fluorouracil and cisplatinum in advanced gastric carcinomas. A phase II trial with prognostic factor analysis. Eur J Cancer 1994;30A:1263-9.

30. Koizumi W, Narahara H, Hara $T$, Takagane A, Akiya $T$, Takagi M, et al. S-1 plus cisplatin versus S-1 alone for first-line treatment of advanced gastric cancer (SPIRITS trial): a phase III trial. Lancet Oncol 2008;9:215-21.

31. Yokota T, Teshima S, Saito T, Kikuchi S, Kunii Y, Yamauchi H. Borrmann's type IV gastric cancer: clinicopathologic analysis. Can J Surg 1999;42:371-6.

32. Jin M, Lu H, Li J, Shen L, Chen Z, Shi Y, et al. Randomized three-armed phase III study of S-1 monotherapy versus S-1/ CDDP (SP) versus 5-FU/CDDP (FP) in patients (pts) with advanced gastric cancer (AGC): SC-101 study. J Clin Oncol (Meeting Abstracts) 2008;26:221s (abstract 4533).

33. Ilson DH. Docetaxel, cisplatin, and fluorouracil in gastric cancer: does the punishment fit the crime? J Clin Oncol 2007;25: 3188-90. 